\title{
Review of current methods for the detection of Trichomonas in clinical material
}

\author{
J. HESS \\ From the Bacteriology Department, Sefton General Hospital, Liverpool
}

SYNOPSIS Methods of 'wet preparation', stained films, and culture were used to detect trichomonads in vaginal exudate and the results of these methods are compared. A method using a wet preparation and Oxoid no. 2 Trichomonas medium is reliable for routine use.

The correct diagnosis of trichomoniasis has become more important at Sefton General Hospital since the start of a cytology unit for the exfoliative cytology of cervical smears, but the interpretation of smears is rendered more difficult by the presence of trichomonads.

It was therefore decided to review the current methods of detecting trichomonads and to assess their reliability for routine use.

Specimens of vaginal discharge were received on sterile cotton wool swabs from patients with vaginal infections (or suspected infections). Two smears were prepared from the vaginal material on microscope slides, and fixed by immersing in ethyl alcohol for 15 minutes. One of the smears was stained by Leishman's stain and the other by Papanicolau's method. The remaining material was suspended in approximately $1 \mathrm{ml}$ of sterile quarter-strength Ringer's solution, and was used for the wet preparation and for inoculating Trichomonas culture media. Ringer's solution was used as it was thought that physiological saline might be slightly antagonistic to trichomonads (Stenton, 1957).

\section{METHODS AND MATERIALS}

WET PREPARATION The suspension of the vaginal material in sterile quarter-strength Ringer's solution was warmed slightly to activate any trichomonads present. A few drops of this suspension were examined microscopically for trichomonads.

LEISHMAN-STAINED FILMS Two volumes of buffered distilled water $(p \mathrm{H} 6 \cdot 8)$ were mixed with one volume of Leishman stain. This solution was added to an alcoholfixed film and left for 15 minutes. The stain was washed off, and the slide dried by blotting. The film was examined microscopically for trichomonads using a $2 \mathrm{~mm}$ oil immersion lens.

Received for publication 20 May 1968.
PAPANICOLAU-STAINED FILMS The second alcohol-fixed smear was stained using a Shandon-Elliott staining machine. After processing the smears were left immersed in xylol until they were mounted. The films were examined microscopically for the presence of trichomonads and cellular changes indicative of trichomoniasis.

TABLE I

RESULTS USING SHANDON-ELLIOTT MACHINE

\begin{tabular}{llc} 
& Reagent & Time $($ min $)$ \\
\hline 1 & $95 \%$ alcohol & $2 \cdot 0$ \\
2 & Distilled water & $2 \cdot 0$ \\
3 & Harris haematoxylin & $3 \cdot 0$ \\
4 & Distilled water & $2 \cdot 0$ \\
5 & $70 \%$ alcohol & $2 \cdot 0$ \\
6 & $1 \%$ acid alcohol & (quickest change) \\
7 & $70 \%$ alcohol & $2 \cdot 0$ \\
8 & Ammonia alcohol & $1 \cdot 5$ \\
9 & $70 \%$ alcohol & $2 \cdot 5$ \\
10 & $95 \%$ alcohol & $1 \cdot 5$ \\
11 & $95 \%$ alcohol & $2 \cdot 0$ \\
12 & O G 61 & $1 \cdot 5$ \\
13 & $95 \%$ alcohol & $1 \cdot 5$ \\
14 & $95 \%$ alcohol & $1 \cdot 5$ \\
15 & E A 50 & $2 \cdot 0$ \\
16 & $95 \%$ alcohol & $1 \cdot 5$ \\
17 & Absolute alcohol & $1 \cdot 5$ \\
18 & Absolute alcohol & $1 \cdot 5$ \\
19 & Xylol & $2 \cdot 0$ \\
20 & Xylol & $3 \cdot 0$
\end{tabular}

${ }^{1}$ The recommended stains are supplied by Ortho Pharmaceuticals. 'The ammonia alcohol was a $3 \%$ solution of 0.880 ammonia in $70 \%$ alcohol.

CULTURAL METHODS FOR TRICHOMONAS In order to select a medium suitable for routine use, five different types of Trichomonas media were employed:

Thomas's medium is a modification of the medium of Feinberg and Whittington (1957), described by Thomas (1964).

Cysteine-peptone-liver-maltose (CPLM) medium This is described by Johnson and Trussell (1943), and the modification of Smith (1965) was used.

Semi-solid medium Described by Lowe (1965).

Oxoid Trichomonas medium (CM 161) An Oxoid 
modification of the medium of Feinberg and Whittington (1957), and the basal medium was obtained in powder form.

Oxoid Trichomonas medium no. 2 (R27) The medium was obtained ready to use, and is a modification of the medium of Bushby and Copp (1955) and Squires and McFadzean (1962).

The culture media were stored at $4^{\circ} \mathrm{C}$. The inoculum was the suspension of vaginal exudate in quarter-strength Ringer's solution. This was divided equally among the five media, using a sterile Pasteur pipette. Cultures were incubated at $34^{\circ} \mathrm{C}$ and examined daily for five days. The sediment was removed from the bottom of the culture with a sterile pipette and examined microscopically for trichomonads.

CULTURE MEDIA The materials required and methods for making up the media are as follows:

Thomas's medium

Proteolysed liver (Oxoid) ........25 g

Sodium chloride ...........6.5 $\mathrm{g}$

Glucose ................5.0 g

Inactivated horse serum (Burroughs

Wellcome)............. $80 \mathrm{ml}$

Water...................1,000 ml

Penicillin G. . . . . . . . . . . . . 1,000,000 units

Streptomycin.............. $0.5 \mathrm{~g}$

Nystatin................. $0 \cdot 1 \mathrm{~g}$

The $p \mathrm{H}$ was adjusted to 6.4 and the medium sterilized by Seitz filtration. The medium was distributed aseptically into sterile $\frac{1}{\mathrm{Oz}}$. bijou bottles, and the bottles were filled with a minimal air space between the lid and the medium.

Basal CPLM medium

Peptone (Oxoid). ............. $32 \mathrm{~g}$

Maltose ................ $1.6 \mathrm{~g}$

Liver digest (Oxoid) ..........20 g

Cysteine hydrochloride .........2.4 g

$\$$ strength Ringer's soln .......... $1,000 \mathrm{ml}$

$\mathrm{N}$-sodium hydroxide soln ........ approx. $9 \mathrm{ml}$

The ingredients were dissolved by shaking, and the $p \mathrm{H}$ adjusted to 6.0. After steaming for 30 minutes at $100^{\circ} \mathrm{C}$ the medium was filtered through a Whatman's no. 1 filter paper, bottled in $90 \mathrm{ml}$ amounts, and autoclaved at $115^{\circ} \mathrm{C}$ for 10 minutes. This base was stable for several weeks.

The penicillin/streptomycin solution is made up of:

Penicillin $\ldots \ldots \ldots \ldots \ldots \ldots \ldots 1 \times 10^{5}$ units

Streptomycin .............. $0 \cdot 1 \mathbf{g}$

Sterile water .............. $10 \mathrm{ml}$

The nystatin suspension contains:

Nystatin. . . . . . . . . . . . . $5 . \ldots 10^{4}$ units

Sterile water ............... 10 ml

The antibiotic solutions were stable for up to 10 days when stored at $4^{\circ} \mathrm{C}$.

The complete medium contains:

Basal medium .............90 ml

Sterile inactivated horse serum

(Burroughs Wellcome) .......10 ml

Penicillin/streptomycin soln $\ldots \ldots \ldots 1 \mathrm{ml}$

Nystatin suspension............1 ml

The medium was mixed and distributed in sterile $\downarrow$ oz bijou bottles.
Semi-solid medium

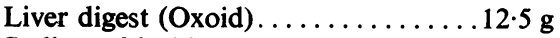

Sodium chloride ............2.5 g

Maltose .................. 0.5 g

Distilled water .............500 ml

The solids were dissolved by heat and the $p H$ wa adjusted to $\mathbf{6 \cdot 2}$.

Of agar powder, $12.5 \mathrm{~g}$ was added and the mixtue steamed at $100^{\circ} \mathrm{C}$ for one-and-a-half hours with frequent mixing. The medium was cooled to $54^{\circ} \mathrm{C}$ and the following added aseptically:

Sterile inactivated horse serum

(Burroughs Wellcome) .......50 ml

Fildes extract (Oxoid) .......... $0.5 \mathrm{ml}$

$1 \%$ sterile streptomycin solution $\ldots .5 \mathrm{ml}$

$1 \%$ sterile chloramphenicol solution. $.5 \mathrm{ml}$

$1 \%$ sterile neomycin solution. .....5 ml

$0.5 \%$ sterile (fresh) nystatin

suspension............... $10 \mathrm{ml}$

The medium was mixed and distributed asepticall

into sterile $\frac{1}{\mathrm{oz}}$ bijou bottles.

Oxoid Trichomonas medium (CM 161)

Liver digest $\ldots \ldots \ldots \ldots \ldots \ldots \ldots .25 \cdot 0 \mathrm{~g} / \mathrm{l}$

Sodium chloride ...........6.5 g/l

Dextrose .................5.0 g/l

Ionagar no. $2 \ldots \ldots \ldots \ldots \ldots \ldots .6 \mathrm{~g} / \mathrm{l}$

Of the base powder, $37.5 \mathrm{~g}$ was added to 1 litre of distilled water and soaked for 15 minutes. The medium was sterilized by autoclaving at $121^{\circ} \mathrm{C}$ for 15 minute

It was cooled to $54^{\circ} \mathrm{C}$ and the following added:

Sterile inactivated horse serum

(Burroughs Wellcome) .......80 ml

Penicillin $\ldots \ldots \ldots \ldots \ldots \ldots \ldots \ldots \ldots 1,000,000$ units

Streptomycin. . . . . . . . . . . 500,000 units

The medium was mixed and distributed aseptically

into sterile $\frac{1}{4}$ oz bijou bottles.

Oxoid Trichomonas medium no. 2 (R27)

Liver infusion ............18.0 g

Hartley digest broth $\ldots \ldots \ldots \ldots \ldots 1,000 \mathrm{ml}$

Horse serum ..............250 ml

Calcium pantothenate, $0.5 \% \mathrm{w} / \mathrm{v} \ldots \ldots 1 \mathrm{ml}$

Dextrose .................20.0 g

Chloramphenicol .............0.125 g $p \mathrm{H}=6.2$ (approx.)

This culture medium was supplied by the manu facturers ready to use.

\section{RESULTS}

Eight methods were employed in the detection of trichomonads. One method involved the use of wet preparation, two made use of stained films and five of culture media. The results of the survey are shown in Table IIa.

One hundred and thirty-two swabs were examineof and in addition eight urine deposits containing trichomonads (Table IIb).

During the survey cultures were examined daip for five days, and the Oxoid no. 2 medium gave $\$$ majority of positive results $(96 \%)$ after three days incubation at $34^{\circ} \mathrm{C}$ (Table III). 
TABLE IIa

RESULTS OF SURVEY USING SWABS OF VAGINAL EXUDATE Method No. of Positives

Wet preparation

Leishman film

Papanicolau film

Thomas's medium

Oxoid medium (CM 161)

Oxoid no. 2 medium (R27)

CPLM medium

Semi-solid medium

TABLE IIb

RESULTS OF SURVEY USING POSITIVE URINE DEPOSITS

Method

No. of Positives

Wet preparation

Leishman film

Papanicolau film

Thomas's medium

Oxoid medium (CM 161)

Oxoid no. 2 medium (R27)

CPLM medium

Semi-solid medium

8

8

3

3

2

8
3

3

TABLE III

RESULTS WITH OXOID NO. 2 MEDIUM

Incubation Time (days)

No. Positive

$\begin{array}{rr}1 & 6 \\ 2 & 1 \\ 3 & 14 \\ 4 & -1\end{array}$

Total detected $=22$

\section{DISCUSSION AND CONCLUSION}

The microscopical detection of trichomonads by either wet preparation or direct smear alone was not satisfactory. The successful use of a wet preparation depends mainly on the correct collection of the specimen, the amount of material on the swab, the alertness of the observer, and the presence and number of motile parasites in the specimen. Thus this method by itself is not to be recommended as a routine procedure.

The staining procedures used during this survey did not yield reliable enough results for routine use. The Papanicolau film may show cellular changes suggesting infestation of the vagina with trichomonads when the parasites are not easily seen. Such changes are not readily recognized by untrained observers and may, in any case, be obscured by cellular deterioration if there is a delay between collection and examination of the specimen.
The methods involving culture media in the detection of trichomonads in this survey were the most successful. Of the five types used, the Oxoid no. 2 medium gave the highest number of positive results. This medium has the added advantage of being supplied by the manufacturers ready to use. The training of laboratory staff to detect the parasite by culture is relatively easy.

The following procedure is a successful routine method for detecting trichomonads:

1 The specimens of vaginal exudate are collected on sterile cotton wool swabs.

2 A suspension of the vaginal material prepared in approximately $1 \mathrm{ml}$ of sterile quarter-strength Ringer's solution is examined microscopically for the parasites.

3 If the wet preparation is negative then the material should becultured using Oxoid Trichomonas medium no. 2 (R27). A heavy inoculum should be used in the broth, ie, the swab stick end and remaining suspension of exudate.

4 Cultures should be incubated at $34^{\circ} \mathrm{C}$, and examined daily for three days (as described previously).

This technique is simple to use and is not time consuming. Heavy infestations may be detected more quickly by the wet preparation, and lighter infestations detected within three days by culture. It is easy to train technicians how to use this method, and it is not necessary to prepare large quantities of culture media.

I wish to thank Mr R. F. Millet, Mr P. E. Cox and the laboratory staff at Sefton General Hospital for their assistance, and also Miss A. M. Williams of the Liverpool College of Technology for her constructive criticism.

This work was carried out during the industrial training period of a sandwich course at the Liverpool College of Technology.

\section{REFERENCES}

Bushby, S. R. M., and Copp, F. C. (1955). J. Pharm. Pharmacol., 7, 112.

Feinberg, J. G., and Whittington, M. J. (1957). J. clin. Path., 10, 327. Johnson, G., and Trussell, R. E. (1943). Proc. Soc. exp. Biol. (N.Y.), 54, 245.

Lowe, G. H. (1965). J. clin. Path., 18, 432.

Smith, K. (1965). In Medical Microbiology, edited by R. Cruickshank 11 th ed., p. 774. Livingstone, Edinburgh and London.

Squires, S., and McFadzean, J. A. (1962). Brit. J. vener. Dis., 38, 218.

Stenton, P. (1957). J. med. Lab. Technol., 14, 228.

Thomas, P. M. (1964). Ibid., 21, 46.

\section{ADDENDUM}

The recommended method for the detection of Trichomonas has been adopted at Sefton General Hospital, and the following data have become avail- 
TABLE IV RESULTS WITH RECOMMENDED METHOD

$\begin{array}{ll}\text { Swab } & \begin{array}{l}\text { Positive by Wet Positive by } \\ \text { Preparation Only Culture Only }\end{array}\end{array}$

Total No. Positive

306 examined by wet preparation only 510 examined by recommended routine

-

38 able since the completion of this project (Table IV) It can be seen that using a method of wet preparation only, positive specimens were an average of $4.7 \%$ of the total received. Using the recommended methoof? of wet preparation and culture, the number op positive specimens detected has increased to $11.2 \%$ of the total received. 